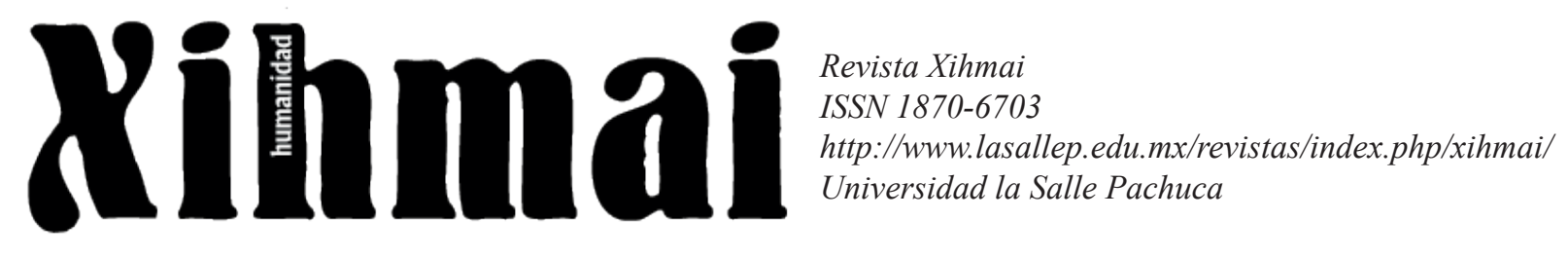

¿DEMOCRACIA Y ABSTENCIONISMO EL CONTRASENTIDO DEL SIGLO XXI DEMOCRACY AND ABSTENTIONISM THE COUNTERSENSE OF THE XXI CENTURY

Pedro Liedo Galindo

Universidad la Salle Pachuca

Nota sobre el autor

Contador Público y Licenciado en Pedagogía, profesor universitario desde 1978, en diversas instituciones de México, D.F. y Pachuca, Hgo. Socio, fundador y director de diversas empresas. Actualmente Rector de la Universidad La Salle Pachuca.

Esta investigación fue financiada con recursos del autor.

Remita cualquier duda sobre este artículo al siguiente correo electrónico: pliedo@lasallep.edu.mx

Recibido:1/1/2006

Aceptado:1/1/2006

Derechos de autor (C) 2006 Universidad La Salle Pachuca - Todos los derechos reservados.

Condiciones de Uso: La reproducción total o parcial de la obra en soporte electrónico queda prohibida sin la autorización de la Universidad la Salle Pachuca. 


\section{DEMOCRACIA Y ABSTENCIONISMO \\ EL CONTRASENTIDO DEL SIGLO XXI}

Pedro Liedo Galindo*

\section{Resumen.}

La democracia ha sido entendida tradicionalmente como el gobierno de las mayorías, sin embargo los altos índices de abstencionismos que hoy se presentan en México y Latinoamérica en su conjunto, cuestionan este concepto, ya que en una elección con alto grado de abstencionismo, el ganador lo hace sin el apoyo de la mayoría de electores.

\section{Abstract}

Democracy has been tradicionally understood as the goverrnment of mayorities, but today the high index of abstencionism in Mexico and Latinamerica questions this idea because in an election with a low range of participation, the winner does not have the support of electors.

\section{1.- Introducción.}

El diccionario de la Real Academia define a la democracia como "Doctrina política favorable a la intervención del pueblo en el gobierno" 111 .

Etimológicamente democracia significa "gobierno del

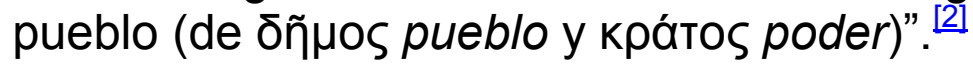

De la primera definición hay que resaltar la palabra intervención, cuya connotación es más intensa que la de participación.

Intervenir es venir entre, estar entre, meter entre, un poco entrometerse; participar es tomar parte o hacer cada quien su parte, la parte que le corresponde. Intervenir es más fuerte que participar. Pero sea intervenir o participar, el elemento esencial de la democracia es 
que el pueblo, como conjunto de ciudadanos y no como una entelequia (en su sentido irónico, no filosófico), asuma su papel en el gobierno, trabajando, opinando, denunciando, exigiendo, votando, interviniendo, en una palabra: participando, haciendo su parte.

Estado es igual a gobierno y sociedad. Esto puede entenderse como una ecuación: gobierno más sociedad, en donde puede ocurrir que cuando uno de estos dos elementos crece, lo hace a costa del otro. A mayor gobierno, menor sociedad y viceversa. Obviamente lo ideal sería un equilibrio de fuerzas, pero cuando la sociedad endosa su responsabilidad al gobierno, lo hace más fuerte $y$, por consecuencia, más autoritario, pero no más eficiente. Cuando alguien deja de participar, simplemente está cediendo, o mejor, regalando su espacio a otro, que sin duda lo tomará.

La democracia también puede entenderse como el gobierno de la mayoría, las mayorías mandan. En los sistemas democráticos los gobernantes y los representantes populares acceden al poder a través del voto en las elecciones. Las democracias modernas han incorporado otros mecanismos como el referéndum y el plebiscito, que lo que buscan es conocer el punto de vista de la población en su conjunto. Sin embargo, parece ser que a una gran parte de los ciudadanos no les interesa la política o les interesa cada vez menos, lo cual, al menos teóricamente es una paradoja: hoy estamos viviendo la democracia, sin participación de las mayorías. Al menos este hecho es contradictorio a la definición conceptual.

Un elemento básico en la participación ciudadana, es el ejercicio del derecho al voto. No es el único, pero es el más elemental y puede ser un buen principio.

En México, tendremos un proceso de sucesión presidencial el próximo dos de julio de este 2006, que puede, muy bien, ejemplificar esta idea. Cuando se ve un panorama como el de la encuesta de DATA $^{[3]}$, solamente un poco más de la mayoría, el cincuenta y cinco por ciento de los entrevistados muestra intención de votar y el resto, casi la mitad: el cuarenta y cinco por ciento ha decidido no votar y que del cincuenta y cinco por ciento que votará, el candidato de la mayoría tendrá entre treinta y treinta y cinco por ciento de los votos emitidos, esta mayoría se convierte en diecinueve por ciento.

Un ejemplo que confirma lo anterior, se refiere a las elecciones en Baja California en 2001: "El candidato triunfante, Eugenio Elorduy Walther, obtuvo 266 mil 440 votos, lo que representa el $18 \%$ de los ciudadanos registrados en el listado nominal." 
En las encuestas preelectorales hay un porcentaje, que puede ir del cinco al quince por ciento de la muestra, que dice que va a votar y finalmente no lo hace, por lo que la abstención normalmente es mayor que la que las encuestas manifiestan, por lo que pudiéramos prever, para las elecciones federales de México en julio de 2006, una abstención mayor al cincuenta por ciento. El próximo presidente de nuestro país resultará electo por menos del veinte por ciento de los mexicanos que conforman la lista nominal de electores.

Este horizonte numérico significa que el próximo presidente de México será elegido, en el mejor de los casos, por uno de cada cinco ciudadanos, si no es que seis y claramente eso no es una mayoría, lo cual ocurre porque los que no votan ceden su espacio a los que sí, lo cual agrava el problema.

Lo que está ocurriendo es que el fenómeno del abstencionismo está atacando fuertemente el concepto de democracia, como gobierno de mayorías.

\section{2.- Panorama.}

El problema de una democracia que se fundamenta en procesos electorales con índices de abstención cercanos o mayores a la mitad de los electores, es serio, pues las minorías se han convertido en la fuerza que decide el tipo de gobierno, la persona que ha de representarlo y el rumbo de la nación. Esto contradice el sentido original de las democracias, pues ya no mandan las mayorías, sino las minorías que han decidido no ceder sus espacios a otros.

Hasta, un poco en broma, se podría recomendar a la Real Academia Española que mejore la definición de democracia, por algo así como lo siguiente: Democracia es una doctrina política favorable a la intervención de una parte del pueblo en el gobierno.

Después habría que decir cuál es esa parte: la que quiere ser parte, la que tiene interés, la que quiere participar.

El que tiene el poder de votar tiene también el poder de no votar. Esta cesión de poder puede darse de manera consciente y voluntaria o puede darse también de manera irreflexiva. Finalmente lo que está ocurriendo es que la mayoría de los ciudadanos está cediendo el poder de su voto a una minoría que decide ejercerlo.

Paradójicamente han mejorado los procesos electorales en términos de transparencia y credibilidad, pero la abstención ha aumentado o en el mejor de los casos, no ha disminuido. 
3.- Abstencionismo.

En política, el abstencionismo es la decisión de no ejercer el derecho al voto en las elecciones. Es decidir no decidir. Por ello es necesario conocer el tamaño del problema.

El listado nominal de electores constituye el universo de los posibles votantes en México. También existe el concepto de Padrón Electoral, que incluye a quienes se les ha suspendido el derecho al voto o han perdido la nacionalidad y a quienes no recogieron su credencial, habiéndola tramitado, así como las credenciales duplicadas.

Para las elecciones federales en México, de julio de 2006, el Padrón Electoral es de 71,994,940 y el Listado Nominal de $70,582,612^{[5]}$

Un valor adicional de la credencial de elector es que sirve como medio de identificación y se le considera como la identificación más confiable para todo tipo de trámites.

Tabla 1. Millones de mexicanos en la lista nominal de electores. ${ }^{[6]}$

\begin{tabular}{|l|l|l|l|l|l|l|}
\hline Nivel & 1991 & 1994 & 1997 & 2000 & 2003 & 2006 \\
\hline Nacional & 36.7 & 45.7 & 52.2 & 58.8 & 64.7 & 70.6 \\
\hline Hidalgo & 0.8 & 1.0 & 1.2 & 1.3 & 1.5 & 1.6 \\
\hline
\end{tabular}

El listado nominal creció veinticuatro por ciento de 1991 a 1994; de 1994 a 1997 lo hizo en catorce por ciento; de 1997 a 2000 en doce por ciento; de 2000 a 2003 en diez por ciento y de 2003 a 2006 en nueve por ciento. En el 2006 habrá once millones de neovotantes para la elección federal, es decir ciudadanos que podrán participar por primera vez en una elección para senadores y presidente, pero si las tendencias se mantienen, sólo votarán cuatro millones de esos diez, ya que el grupo de jóvenes es el que tiene mayores índices de abstencionismo. De estos once millones, cinco pudieron votar en las elecciones federales de 2003, cuyo índice de abstención fue del sesenta por ciento, dos puntos porcentuales por encima de la media nacional. Esto es muy importante, ya que tradicionalmente se piensa que los jóvenes son los más participativos y no es así.

La abstención en México y en el Estado de Hidalgo se ha comportado de la siguiente manera: 
Tabla 2. Porcentaje de abstención en las últimas elecciones federales. $\frac{3}{-}$

\begin{tabular}{|l|l|l|l|l|l|}
\hline Nivel & 1991 & 1994 & 1997 & 2000 & 2003 \\
\hline Nacional & 34 & 23 & 42 & 36 & 58 \\
\hline Hidalgo & 38 & 23 & 44 & 38 & 61 \\
\hline
\end{tabular}

Estrictamente estas cinco elecciones no serían comparables entre sí, dado que las de 1991, 1997 y 2003 se refieren a las llamadas elecciones intermedias, en las cuales sólo se eligen a los diputados federales y en las elecciones de 1994 y 2000, se eligieron diputados, senadores y presidente de la república. Sin embargo se aprecia que en Hidalgo la abstención es en promedio dos puntos porcentuales mayor que la nacional y estos comportamientos sí son consistentes, aunque con pequeñas variaciones.

Podría pensarse que las elecciones intermedias tienen un menor interés por parte del electorado, pero en la elección de 2000, la abstención fue mayor que en la de 1991 y esto a pesar de las altas expectativas que generaron las elecciones de 2000, por ser las primeras elecciones en que podría no ganar el partido oficial.

Otro punto importante a considerar es que si la madurez política de un país se puede reflejar en el grado de participación electoral, sería dable pensar que el porcentaje de abstención tendería a disminuir con el paso del tiempo y claramente se puede apreciar que esto no es así.

4.- Factores para votar y para no votar.

Riker y Ordeshook $\frac{[7]}{}$, mencionan como factores de la decisión de votar:

1.- Dificultad para votar (costo e inconvenientes del voto para el votante).

2.- Utilidad de votar (Utilidad esperada por el votante).

3.- Fuerza del voto (Probabilidad de que mi voto influya en el resultado).

4.- Beneficio de votar (Qué gano si gana el partido por el que vote).

5.- Valor cultural del voto (Un buen ciudadano vota siempre).

Mencionan estos autores una fórmula que es interesante, pero que habría que adecuar a la realidad mexicana, por ello sólo relacionaremos estos factores con la situación de México. 
La dificultad para votar en México es mínima, ya que el Instituto Federal Electoral (creado en octubre de 1990) ha dado a las credenciales de elector una vigencia indefinida, por lo que, en quince años, el trámite sólo se hace una vez, excepto si se requiere una reposición. En términos generales, a excepción de algunas zonas rurales, el acceso a las casillas de votación es perfectamente realizable. Como veremos más adelante, entre las razones de los abstencionistas, no se menciona ni la dificultad para obtener la credencial de votante, ni el acceso a las casillas. La dificultad para votar es un factor que no se puede considerar como propiciador de abstencionismo en México, pues únicamente se requiere tramitar la credencial de elector, aparecer en el listado nominal y el día de la elección asistir a votar.

La utilidad de votar, es entendida como la percepción que el ciudadano tiene de que tanto su voto individual, como el proceso electoral en su conjunto, sirvan para mejorar las condiciones de vida individual y social. Aquí ha habido una evolución en los argumentos abstencionistas. Antes se decía: "Para qué voto si de todas formas va a ganar el PRI", hoy se dice: "Para qué voto, si todos son iguales". Pero no ha habido una experiencia que favorezca la idea de votar es útil. Más adelante mencionaremos las diferencias en las ofertas de los partidos políticos. Este factor es el que más puntos le abona a la abstención, como se apreciará en las tablas 4, 5 y 6 .

La fuerza del voto no es un factor propiciador, ni inhibidor importante, pues un voto, individualmente considerado, no tendría ningún poder para inclinar el resultado de una elección, en donde votan cientos de miles o millones de personas. Sólo en eventos sumamente reñidos podría dársele algún valor al voto individual, pero para abatir la abstención. Es importante hacer notar que en los procesos electorales transparentes, el ciudadano se da cuenta de que todos los votos cuentan. Mientras la expectativa del votante sea de una elección cerrada, el valor que le otorga a su voto aumenta y, posiblemente, decidiría votar. Cuando las expectativas o las encuestas de opinión, muestran una diferencia considerable, la fuerza del voto, como factor influyente en el ciudadano, disminuye.

El beneficio de votar, esto es, lo que el votante gana, si gana el candidato de su predilección, trata claramente de un interés personal, antes que colectivo, que puede ir desde la obtención o conservación de un empleo, desde el punto de vista personal, hasta mejores niveles de vida, a nivel de grupo. De hecho, México es el país de 
Latinoamérica en donde este factor tiene el más alto valor. Treinta y cinco puntos sobre veintiséis de Paraguay, que ocupa el segundo lugar y casi el doble de la media latinoamericana que es de diecinueve puntos. ${ }^{[8]}$ En este sentido, este factor podría incidir en la disminución del abstencionismo, al menos en nuestro país.

Por último, el valor cultural del voto es que hace que un ciudadano vote siempre o nunca vote. Este es un factor en el cual los procesos de educación cívica, política y democrática, deberán incidir, para que idealmente, en el futuro, todos los ciudadanos consideren que hay que votar siempre.

En Estados Unidos, por ejemplo, en el proceso electoral del año 2004 votaron solamente ciento veintidós millones de ciudadanos que representan el cincuenta y siete por ciento de un padrón de doscientos quince millones de ciudadanos. El índice de abstencionismo fue del cuarenta y tres por ciento, esto es, siete puntos porcentuales por encima de México en 2000. Además la diferencia entre el primero y el segundo lugares fue de solamente 2.46 por ciento. ${ }^{[9]}$, lo que haría pensar en que el factor de la fuerza del voto incidiera en la disminución del abstencionismo, pero aparentemente no fue así.

Analizando, los factores mencionados no podríamos decir que alguno de ellos alentó tan alto índice de abstención en las elecciones norteamericanas de 2004, sobre todo porque existe la impresión de que las ofertas de los partidos Republicano y Demócrata son más similares que las que pudiera haber entre los partidos de diferentes países latinoamericanos.

Vale la pena conocer algunos elementos de una encuesta política realizada en España por el Centro de Investigaciones Sociológicas, que es un organismo autónomo, adscrito al ministerio de la presidencia. ${ }^{[10]}$

Los momentos en que los ciudadanos decidieron no votar en las elecciones de 2004 en España fueron los siguientes:

Tabla 3. Cuándo se decide no votar en España

\begin{tabular}{|l|c|}
\hline Razón & Porcentaje \\
\hline Nunca vota & 42 \\
\hline Lo decidió antes de las campañas & 31 \\
\hline Lo decidió el día de la votación & 12 \\
\hline Lo decidió en la última semana & 6 \\
\hline Lo decidió al comienzo de las campañas & 2 \\
\hline
\end{tabular}




\begin{tabular}{|l|c|} 
No contestó & 7 \\
\hline Total & 100 \\
\hline
\end{tabular}

En las elecciones presidenciales de 2004 en España, el índice de participación fue del setenta y siete por ciento y una abstención del veintitrés por ciento. El atentado de Atocha del 11 de marzo fue un elemento para hacer que la gente fuera a votar, y que los resultados de las encuestas no se cumplieran. La fuerza del voto y el beneficio de votar, factores tres y cuatro, tuvieron una influencia determinante, para que el partido en el poder perdiera en estas elecciones, aunque se perfilaba como el favorito, hasta antes del atentado. También es destacable en la tabla tres, que en España hay casi un diez por ciento $(9.66 \%)$ de ciudadanos que nunca vota: el cuarenta y dos por ciento del veintitrés por ciento. Ésta podría ser una cuantificación del quinto factor: el valor cultural del voto. Es destacable que el índice de participación aumento ocho por ciento con respecto a las elecciones de 2000, que fue del sesenta y nueve por ciento. Esto también se puede atribuir al factor tres, fuerza del voto, por la situación que se vivía después del peor atentado de la España contemporánea.

Cuando se particulariza la pregunta sobre los motivos de abstención electoral, surgen respuestas conocidas, pero la distribución de las mismas, pudiera ser desconocida. Es común atribuir la abstención a una apatía, pero los siguientes datos pudieran reflejar que más bien se trata de una antipatía. Dicho de otro modo: parecería que quienes no votan no lo hacen por falta de interés, sino porque no están de acuerdo con lo que encuentran, la llamada oferta electoral.

Tabla 4. Razones por las que los españoles no votan.

\begin{tabular}{|l|c|}
\hline Razón & Porcentaje \\
\hline No hay alguna alternativa que le satisfaga & 24 \\
\hline $\begin{array}{l}\text { No le inspira confianza ningún partido ni ningún } \\
\text { político }\end{array}$ & 19 \\
\hline Da lo mismo votar que no votar, de nada sirve & 16 \\
\hline Esta harto/a de política y elecciones & 13 \\
\hline Para mostrar descontento & 12 \\
\hline No sabe a quién votar & 2 \\
\hline Otras & 6 \\
\hline No contesta & 8 \\
\hline Total & 100 \\
\hline
\end{tabular}


Al revisar estas razones, las primeras cuatro podrían agruparse en el concepto de utilidad de votar, que es el factor dos. Pero la quinta razón es muy interesante, porque rescata lo que el Premio Nóbel de Literatura, Saramago, llama en su novela "Ensayo sobre la lucidez" [111]: "el voto blanco". Resulta ser, en la novela, que la mayoría (setenta y cinco por ciento) de los votantes de un pueblo, entregan su voto en blanco. La elección se repite y ahora el voto blanco aumenta al ochenta y tres por ciento. Se habla entonces de un "atentado democrático a la democracia" y se realiza una investigación de los "blanqueros", sustantivo que denomina a quienes votaron en blanco. Por supuesto que se trata de una novela, pero de una novela de alguien que entiende de política y que visualiza este problema como un futuro probable. De hecho, en una entrevista que le hizo un periodista de la AFP, al responder la pregunta sobre si el voto en blanco era antidemocrático, el Premio Nóbel de Literatura contestó: "El voto en blanco es igual de democrático que cualquier voto expreso. Si el voto en blanco asusta a los partidos es precisamente por ser democrático. El elector que vota en blanco no puede ser acusado de subversivo, es sencillamente alguien que no está satisfecho con el funcionamiento de la democracia y escoge esa manera de expresarlo. Sólo falta probar su eficacia real." [12]

Ya hay algunas organizaciones que van en esta línea de Saramago, al pretender darle un valor al voto blanco. ${ }^{[13]}$ Esto puede ser muy interesante, si adquiriera fuerza, pues sería un movimiento ciudadano que demostraría a los partidos políticos la necesidad de revisar su actuación. Pero no es un remedio, pues las legislaciones, al menos en Latinoamérica no exigen un mínimo de votos (sí de porcentajes en aquellos países que contemplan segundas vueltas), pero con el voto del candidato, sería suficiente para declararlo ganador, aunque la inmensa mayoría de los votantes hubieran sufragado en blanco. Pero este gobernante, estaría muy preocupado por el resultado y sabría que no tiene poder de convocatoria ni de convencimiento y esto (posiblemente) lo obligaría a realizar un buen trabajo. El voto en blanco puede ser, solamente, un punto de partida para evitar el abstencionismo, propiciar la votación y posteriormente lograr que se mejore la oferta electoral y que los partidos seleccionen mejor a sus candidatos o que seleccionen a mejores candidatos.

En la mayoría de las legislaciones electorales de Latinoamérica, los votos nulos y los votos blancos carecen de valor, hasta ahora. Es 
decir, no invalidan una elección o prevén una segunda vuelta, al alcanzar un nivel determinado o no alcanzar un porcentaje de votos válidos.

Otra encuesta interesante se efectuó en Nicaragua en 2000 $\frac{[14]}{[1}$, país centroamericano con un porcentaje histórico de votación mayor al $80 \%$ y que, sorpresivamente, en las elecciones municipales de 2000 tuvo un abstencionismo del $42 \%$.

Tabla 5. Por qué no se vota en Nicaragua

\begin{tabular}{|l|c|}
\hline Razón & Porcentaje \\
\hline No me interesa & 26 \\
\hline No tenía documento & 24 \\
\hline Inconveniente personal & 21 \\
\hline Son corruptos & 6 \\
\hline Ningún candidato me parecía idóneo & 6 \\
\hline Nunca hacen nada & 5 \\
\hline Prometen y no cumplen & 4 \\
\hline No estoy registrado & 5 \\
\hline Otras & 3 \\
\hline Total & 100 \\
\hline
\end{tabular}

El problema del abstencionismo es mucho más complejo que lo que superficialmente pudiera parecer. Se habla en las campañas electorales de vencer al abstencionismo. El expresidente mexicano Luís Echeverría Álvarez en campaña presidencial, en 1970, acuñó la frase "prefiero un voto en contra que una abstención". En donde queda evidenciado que el fantasma del abstencionismo ronda en las conciencias políticas mexicanas desde hace más de treinta y cinco años.

Después del proceso electoral de 2002, Oscar Fonseca Montoya, Presidente del Tribunal Superior de Elecciones de Costa Rica, al constatar el alto porcentaje de abstencionismo, exclamó: "El electorado nos ha abandonado". ${ }^{[15]}$

Podría decirse, parafraseando a Fonseca que el electorado no solo ha abandonado a la clase política, sino que los ha ignorado, los ha menospreciado, tal vez crea que la situación económica, política y social de un país cada vez depende menos de los líderes que tengan 
la responsabilidad de gobernarlos y más de lo que hagan los ciudadanos.

El área de sondeos de opinión, recientemente creada en la Universidad La Salle Pachuca y que coordina el Lic. Miguel Ángel Maldonado Rico, realizó en marzo de 2006 una encuesta sobre intención de voto $y$, entre otras preguntas, también incluyó una sobre factores para no votar.

Tabla 6. Razones por las que no se vota en Pachuca. ${ }^{[16]}$

\begin{tabular}{|l|c|}
\hline Razón & Porcentaje \\
\hline Porque no hay un verdadero cambio & 24 \\
\hline No le interesa & 15 \\
\hline Los candidatos no inspiran confianza & 14 \\
\hline $\begin{array}{l}\text { Los candidatos no toman en cuenta a la } \\
\text { gente }\end{array}$ & 13 \\
\hline Porque hay fraude electoral & 10 \\
\hline $\begin{array}{l}\text { Los candidatos no tienen buenas } \\
\text { propuestas }\end{array}$ & 9 \\
\hline Los gobernantes no trabajan bien & 5 \\
\hline No tengo tiempo & 4 \\
\hline No sabe & 6 \\
\hline Total & 100 \\
\hline
\end{tabular}

También es interesante conocer el otro punto de vista, es decir, la opinión de quienes sí votan. En México Consulta Mitofsky realizó una encuesta en septiembre de 2003, después de las últimas elecciones federales que hemos tenido, para conocer las razones por las que la gente vota, pudiendo resumirse así:

Tabla 7. Razones por las que se vota en México por un partido determinado. $\stackrel{[17]}{ }$

\begin{tabular}{|l|c|c|c|}
\hline Razón & PAN & PRD & PRI \\
\hline Siempre voto por el mismo Partido & 23 & 12 & 58 \\
\hline $\begin{array}{l}\text { Fox los decepcionó y rechazan al } \\
\text { PRI }\end{array}$ & & 19 & \\
\hline Para apoyar al Presidente VFQ & 36 & & \\
\hline
\end{tabular}




\begin{tabular}{|l|c|c|c|}
$\begin{array}{l}\text { Para apoyar al Jefe de Gobierno } \\
\text { AMLO }\end{array}$ & & 36 & \\
\hline Porque gobernaba mejor & & & 14 \\
\hline Porque tiene mejores candidatos & 2 & 2 & 2 \\
\hline $\begin{array}{l}\text { Porque hace las mejores } \\
\text { propuestas }\end{array}$ & 10 & 20 & 7 \\
\hline Porque es menos malo & 15 & & \\
\hline Otras razones & 5 & 5 & 7 \\
\hline No sabe o no contesta & 9 & 6 & 12 \\
\hline Totales & 100 & 100 & 100 \\
\hline
\end{tabular}

La ciudadanía ha quedado desencantada, a base de ejemplos, de lo que los políticos pueden hacer y le ha quedado clara la diferencia entre una promesa de campaña y la realidad posterior. Por un lado hay una tendencia cada vez mayor a confiar en la legalidad de las elecciones; hay un sentimiento de fiabilidad en las instituciones electorales. Pero por el otro, los ciudadanos saben, cada vez más, que votar por algún candidato no es garantía de la eficacia de su gestión. La tendencia es votar por el que le parezca menos corrupto o por quien se crea que va a resultar el menos nefasto o peligroso. También es necesario mencionar el llamado "voto útil", al que hace referencia el factor tres, que es cuando el votante considera que su opción no tiene posibilidades reales de triunfo y prefiere darle fuerza a su voto, apoyando al candidato o partido que tenga más posibilidades de triunfo en una elección que se presenta, por las encuestas, como muy reñida.

Ante la perspectiva del desencanto entre la oferta en las campañas y los resultados en la realidad, parece que abstenerse resulta una postura lógica y hasta congruente, pues si lo que se ofrece en el panorama electoral no satisface las expectativas del elector, cualquiera que gane dará resultados similares, a esto hace referencia el factor dos.

Es claro que no todo mundo puede votar. Hay causas del abstencionismo que pudieran considerarse normales y que en su conjunto pueden resultar significativas, pero nunca alarmantes.

Las principales pudieran ser: la gente que está fuera del domicilio en donde debe votar, los que están enfermos o incapacitados para emitir su voto, los que se encuentran trabajando, los que han perdido o no encuentran el día de la elección su credencial, los que no aparecen 
en el listado nominal de electores (estas últimas dos condiciones son requisito indispensable para emitir el sufragio en México), las cuestiones climáticas, los que han fallecido, otros eventos, como el que se menciona para las elecciones federales de 2006: el campeonato mundial de fútbol y otros más, como pueden ser presiones familiares o políticas. Sería interesante realizar, de manera paralela a las encuestas de salida, una investigación dirigida a quienes no votan, para conocer estas causas, buscándolos en sus casas.

El 12 de marzo de 2006 se llevaron a cabo elecciones en el Estado de México, que es la entidad de la federación con mayor número de electores. Tradicionalmente se ha considerado esta elección, como una especie de anticipo de lo que ocurrirá en las siguientes elecciones federales. Los niveles de abstención fueron muy altos: cincuenta y nueve por ciento en promedio, entre las municipales $(58.75 \%)$ y las distritales (59.50\%).

Una breve revisión del panorama latinoamericano puede servirnos de referencia.

Tabla 8. Niveles de abstención en algunos países latinoamericanos.

\begin{tabular}{|c|c|c|c|}
\hline País & Año & $\begin{array}{l}\text { Porcenta } \\
\text { je }\end{array}$ & Fuente \\
\hline Argentina & $\begin{array}{l}200 \\
3\end{array}$ & 22 & $\begin{array}{l}\text { http://www.mininterior.gov.ar/elecciones/archivos_xls/TotPais } \\
\text { 2003.xls }\end{array}$ \\
\hline Bolivia & $\begin{array}{l}200 \\
5\end{array}$ & 16 & http://www.cne.org.bo/sirenacomp/index.aspx \\
\hline Brasil & $\begin{array}{l}200 \\
2\end{array}$ & 56 & http://www.tse.gov.br/ \\
\hline Chile & $\begin{array}{l}200 \\
5\end{array}$ & 13 & http://www.elecciones.gov.cl/Sitio2005_2v/index.html \\
\hline Colombia & $\begin{array}{l}200 \\
2\end{array}$ & 54 & http://www.registraduria.gov.co/ \\
\hline $\begin{array}{l}\text { Costa } \\
\text { Rica }\end{array}$ & $\begin{array}{l}200 \\
6\end{array}$ & 34 & http://www.tse.go.cr/escrutinio_f2006/Presidenciales/0.htm \\
\hline Ecuador & $\begin{array}{l}200 \\
2\end{array}$ & 29 & $\begin{array}{l}\text { http://www.tse.gov.ec/elec2002/2da_vuelta/resul_presidentes } \\
\text {.html }\end{array}$ \\
\hline \begin{tabular}{|l|} 
El \\
Salvador
\end{tabular} & $\begin{array}{l}200 \\
4\end{array}$ & 33 & http://www.jve.gob.sv/ \\
\hline $\begin{array}{l}\text { Guatemal } \\
\text { a }\end{array}$ & $\begin{array}{l}200 \\
3\end{array}$ & 47 & http://www.tse.org.gt/resultados2003.htm \\
\hline Honduras & $\begin{array}{l}200 \\
5\end{array}$ & 54 & http://www.resultados.tse.hn/ \\
\hline México & $\begin{array}{l}200 \\
0\end{array}$ & 36 & http:// www.ife.org.mx \\
\hline Nicaragua & $\begin{array}{l}200 \\
1\end{array}$ & 11 & http://www.cse.gob.ni/ \\
\hline
\end{tabular}




\begin{tabular}{|l|l|c|l|} 
Panamá & $\begin{array}{l}200 \\
4\end{array}$ & 23 & http://www.tribunal-electoral.gob.pa./elec.html \\
\hline Paraguay & $\begin{array}{l}200 \\
3\end{array}$ & 36 & http://www.tsje.gov.py/ \\
\hline Perú & $\begin{array}{l}200 \\
6\end{array}$ & 17 & http://www.elecciones2006.onpe.gob.pe/ \\
\hline $\begin{array}{l}\text { R. } \\
\text { Dominica } \\
\text { na }\end{array}$ & $\begin{array}{l}200 \\
4\end{array}$ & 27 & http://www.jce.do/Boletines2004/Boletines/B10.html \\
\hline $\begin{array}{l}\text { Uruguay } \\
200 \\
4\end{array}$ & 10 & http://www.corteelectoral.gub.uy/nacionales20041031/ \\
\hline $\begin{array}{l}\text { Venezuel } \\
\text { a }\end{array}$ & $\begin{array}{l}200 \\
0\end{array}$ & 44 & http://www.cne.gov.ve/estadisticas/e015.pdf \\
\hline
\end{tabular}

Para hacer comparables las cifras de abstencionismo de un país a otro es necesario conocer el grado de obligatoriedad en su legislación electoral. Ya que no es lo mismo que no exista presión o sanción por no ir a votar a que si exista y que puede ser una multa, arresto, impedimento para realizar gestiones o trámites gubernamentales, suspensión de derechos u otros, como la imposibilidad de realizar transacciones bancarias (Perú, Artículo 9 de la Ley Orgánica de Elecciones)

Las leyes de Colombia, Costa Rica, El Salvador, Guatemala, Nicaragua, Panamá, República Dominicana y Venezuela no contemplan sanciones a quienes no voten. En Colombia, incluso, existen privilegios desde 1997 para quien vote, que van desde preferencias en la selección laboral, hasta descanso de media jornada ${ }^{[18]}$. Aún así, los índices de abstencionismo son de los más altos de Latinoamérica, ver tabla 8.

Bolivia, Brasil, Honduras, México y Paraguay normalmente no aplican las sanciones previstas en sus leyes a quienes no ejerzan el derecho al voto.

Argentina, Chile, Ecuador, Perú y Uruguay cuentan con sanciones y las aplican a quienes no sufraguen. ${ }^{[19]}$ En la elección presidencial de 2006 en Perú, se registró un doce por ciento de votos en blanco, el más alto registrado en Latinoamérica, lo que puede ser un indicio de que la tendencia del voto blanco vaya en aumento.

Hay países como Argentina (Artículo 12 del Código Electoral Nacional), Bolivia (Artículo 10 del Código Electoral), Chile ( Artículo 15 de la Constitución Política de la República) o Uruguay (Punto segundo del Artículo 77 Constitucional), en donde expresamente se dice que el 
voto es una obligación. Existen sanciones para quien no cumpla con esta obligación. Por ello la abstención es significativamente más baja que en aquellos países en donde no hay sanciones o éstas no se aplican.

El caso de México es ambiguo: de acuerdo con nuestras leyes, votar es una prerrogativa (Fracción I del artículo 35 de la Constitución Política de los Estados Unidos Mexicanos), pero también es una obligación (Fracción III del artículo 36 constitucional). El artículo 38, en la fracción I, del texto constitucional, establece como causas de suspensión de los derechos o prerrogativas ciudadanas, la falta de cumplimiento, sin causa justificada, de cualquiera de las obligaciones que impone el artículo 36. "Esta suspensión durará un año y se impondrá además de las otras penas que por el mismo hecho señalare la ley". [20]

De lo anterior se desprende que efectivamente la Constitución Mexicana establece sanciones a quienes se abstengan de votar en las elecciones. Sin embargo, en la práctica, tales sanciones nunca se han aplicado. Al menos no existe evidencia de ello.

Pero lo que casi parece cómico es que en México al que no vote lo castigarán sin votar un año. Ambiguo y santo remedio. Letra muerta.

Los derechos tienen siempre una obligación asociada. Tengo el derecho a recibir educación (artículo 3 constitucional), pero tengo la obligación de contribuir para los gastos públicos (fracción IV del artículo 31 constitucional). Sin embargo con el ejercicio del sufragio, al menos en la Constitución Mexicana, no ocurre así, pues la misma acción, votar, es derecho y obligación. No hay una relación de correspondencia,

En la legislación específica, el punto tres del artículo cuatro del Código Federal de Instituciones y Procedimientos Electorales (mejor conocido como Cofipe), textualmente dice: "Quedan prohibidos los actos que generen presión o coacción a los electores.", lo que se podría entender como la imposibilidad de sancionarlos por no votar.

5.- Similitud en la oferta electoral.

Independientemente del trabajo de difusión que realicen los partidos políticos, un elemento fundamental para emitir un voto razonado sería el conocer la ideología en que pretenden sustentar su trabajo, lo que tiene relación con el factor cuatro. La ideología de los 
Partidos Políticos mexicanos está contenida en un documento llamado declaración de principios. Por la extensión y naturaleza de este trabajo, solamente se enunciarán los puntos que constituyen esta declaración, que pueden ser una base de comparación. Se presentan por orden alfabético únicamente los cinco partidos políticos que contendrán en las elecciones federales de 2006.

5.1.- Alternativa Socialdemócrata y Campesina. ${ }^{[21]}$

- Desarrollo Político.

- Desarrollo Económico.

- Desarrollo Social.

- Relaciones con el mundo.

5.2.- Nueva Alianza. ${ }^{[22]}$

- Principios Políticos.

- Principios Económicos.

- Principios Sociales.

5.3.- Partido Acción Nacional. ${ }^{[23]}$

- Persona y libertad.

- Política y responsabilidad social.

- Familia.

- Cultura y Educación.

- Nación y mundialización.

- Desarrollo humano sustentable.

- Humanismo Económico.

- Trabajo.

- Medio Ambiente.

- Ciencia e innovación tecnológica.

- Humanismo bioético.

- Campo y ciudad.

- Municipio y sistema federal.

5.4.- Partido de la Revolución Democrática. ${ }^{[24]}$

- Historia e identidad.

- El Partido, instrumento de la sociedad.

- Sociedad productiva, justa e igualitaria.

- Equidad de género.

- Trabajo, valor esencial.

- Conquistar la democracia. 
- Desarrollo sustentable.

- Independencia y soberanía.

- Cooperación y paz mundiales.

5.5.- Partido Revolucionario Institucional.

- Democracia social.

- Estado social y democrático.

- Soberanía en la globalización.

- Pacto federal.

- Estado Laico.

- Cultura de la legalidad.

- Rectoría del Estado y el mercado.

- Desarrollo sustentable.

- Equidad.

- Pacto político social.

Al leer los puntos de estas declaraciones, resalta en primer lugar que los dos primeros partidos enunciados tienen básicamente los mismos elementos. Son, casualmente, los dos partidos que menores posibilidades tienen de ganar en los comicios de julio de 2006. Hasta podría pensarse que no han decidido claramente una plataforma ideológica y que su máximo objetivo es sobrevivir, con la conservación de su registro y presentarse como una opción difusa y al mismo tiempo diferenciada, sin que quede claro en qué puede consistir su diferenciación con los tres partidos importantes.

Los otros tres partidos, que son los que realmente contienden en la elección presidencial, presentan un esquema en su Declaración un poco más específico.

Ante este primer panorama, que sería deseable que el ciudadano común conociera, es claro que no existen elementos suficientes de juicio como para emitir un voto fundado. El siguiente paso, sería profundizar en estos documentos. Pero al menos, en los tres partidos más grandes, sí se vislumbran elementos ideológicos más claros.

Pero esto se contradice con un fenómeno, si no nuevo en México, sí cada vez más frecuente, que es el cambio de los políticos de un partido a otro, enviando al electorado dos señales claras: la primera, que lo que importa es seguir en la política sin importar en qué partido; y la segunda y más grave, con relación al abstencionismo, ya que refuerza la idea de que no hay diferencia en la ideología de los partidos, es que una persona puede cambiar de partido sin modificar 
su ideología, o que los partidos adaptan su plataforma en función de quienes se adhieren a él y no al revés.

Este fenómeno de cambio de partido o "trapecismo político", que antes era excepcional, hoy se ha vuelto casi norma de conducta, cuando un político tiene problemas principalmente con la dirigencia de su partido. Esto hace ver que desde el punto de vista personal de los políticos es primero su trayectoria y después sus ideales. La lucha es por el poder personal y los partidos políticos se han vuelto solamente la plataforma o "el trampolín" que permite hacerlo.

El otro fenómeno que podía alentar al abstencionismo son las alianzas, en donde los partidos suman fuerzas, y supuestamente electores, para ganar las votaciones, lo que desde el punto de vista del elector es un mensaje claro que lo que buscan es el triunfo, el poder por el poder. Sobre todo cuando las alianzas se dan entre prácticamente todas las combinaciones posibles.

6.- Alternativas:

Ante la situación descrita: un alto abstencionismo, una clara antipatía de la ciudadanía y un creciente desencanto hacia los políticos y sus partidos, cabría la duda sobre la posibilidad de revertir esta tendencia y mejorar la participación.

La participación electoral es la más simple forma de participar en política y es la manera más civilizada en la política moderna, pero existen otras formas de participación política, que tienen la intención de manifestar lo que el ciudadano quiere o piensa.

Como simple enumeración, están las siguientes:

$\S \quad$ Firmar un escrito.

$\S \quad$ Enviar una carta.

$\S \quad$ Participar en una manifestación pública.

$\S \quad$ Bloquear una vía de comunicación.

$\S$ Plantones.

$\S$ Denunciar en los medios de comunicación.

$\S$ Comprar o dejar de comprar un producto o servicio.

$\S \quad$ Llevar alguna insignia.

$\S$ Pegar calcomanías en las casas o vehículos.

$\S$ Pintar bardas.

$\S$ Daños en edificios o vehículos.

$\S$ Enviar, reenviar o adherirse a un correo electrónico.

$\S$ Asistir a reuniones políticas. 
$\S \quad$ Manifestarse frente a una dependencia gubernamental.

Estas formas de participación no electoral pueden llamar la atención sobre un problema particular y hasta pueden lograr acciones por parte de quienes ejercen el poder, pero no inciden directamente en los resultados electorales, cuya intención primordial es definir quién debe gobernar.

También se puede, en México, participar en política sin afiliarse a algún partido político, a través de las Agrupaciones Políticas Nacionales, que se encuentran contempladas en la ley.

En México existen registradas ante el Instituto Federal Electoral ciento siete Agrupaciones Políticas Nacionales, de la más diversa índole.

La legislación establece que para la constitución de una Agrupación Política Nacional (APN) se requieren tres mil afiliados en veinte entidades federales $\mathrm{O}$ trescientos afiliados en doscientos distritos electorales, más otro grupo de requisitos, principalmente para conservar su condición como APN.

Lo que es importante es generar la conciencia de que la participación política es fundamental, que es la mejor y más civilizada manera de manifestarnos en los temas que nos interesan y que nos afectan.

La disminución de los índices de abstencionismo debe ser una meta nacional, que permita a todos los ciudadanos expresarse libre y democráticamente, volviéndole a dar a la democracia su sentido original: el gobierno de las mayorías.

Bibliografía

ALONSO-FERNÁNDEZ Francisco, 2006, El hombre libre y sus sombras, Madrid: Editorial Antropos.

BOBBIO Norberto y MATEUCCI Nicola, 1985, Diccionario de Política, México: Editorial Siglo XXI. 
Constitución Política de los Estados Unidos Mexicanos, 2005, México: Editores Mexicanos Unidos.

RIKER William y ORDESHOOK Peter, 1993, An Introduction to Positive Political Theory,Prentice Hall.

SARAMAGO, José, 2005, Ensayo sobre la lucidez. Madrid: Editorial Alfaguara.

\section{Publicaciones}

www.abstencionactiva.blogspot.com

www.alternativa.org.mx

www.anula-tu-voto.org.mx

www.cis.es

www.confidencial.com

www.consulta.com.mx

www.fec.gov

www.ife.org.mx

www.iidh.ed.cr

www.lasallep.edu.mx

www.latinobarometro.org

www.nueva-alianza.org.mx

www.pan.org.mx

www.prd.org. $m x$

www.pri.org.mx

www.rae.es

www.secretariasenado.gov.co

www.tij.uia.mx

www.tse.go.cr

\footnotetext{
${ }^{[11}$ http://buscon.rae.es/drael/SrvltGUIBusUsual?TIPO_HTML=2\&LEMA=democracia

${ }^{[2]} \mathrm{http}: / /$ www.educa.madrid.org/web/ies.garciamorato.madrid/Diccionario.htm\#D

[3] DATA, Opinión Pública y Mercados, S.C.

${ }^{[4]}$ http://www.tij.uia.mx/elbordo/vol08/elecciones4.html

${ }^{[5]}$ www.ife.org.mx

${ }^{[6]}$ Elaboración propia con datos del Instituto Federal Electoral (IFE)
} 
www.ife.org.mx

${ }^{[7]}$ Riker H., William y Ordeshook C., Peter, An Introduction to Positive Political Theory. Prentice-Hall, 1993.

${ }^{[8]}$ http://www.latinobarometro.org/uploads/media/2005.pdf

${ }^{[9]}$ http://www.fec.gov/pubrec/fe2004/tables.pdf

${ }^{[10]}$ www.cis.es/cis/opencms/-Archivos/Marginales/2580_2599/2588/e258800.html

[11] Saramago, José. Ensayo sobre la lucidez. Ed. Alfagūara, Madrid. 2005

${ }^{[121}$ http://www.abstencionactiva.blogspot.com/

${ }^{[13]}$ Véase: http://www.anula-tu-voto.org.mx/

${ }^{[14]}$ http://www.confidencial.com.ni/cinco/razones5.html

${ }^{[15]}$ http://www.tse.go.cr/

[16] Elaboración propia con datos de: www.lasallep.edu.mx

[17] Elaboración propia, basada en :

http://www.consulta.com.mx/interiores/15_otros_estudios/raz_voto.html

${ }^{[18]}$ http://www.secretariasenado.gov.co/Acto_legislativo.asp

${ }^{[19]}$ http://www.latinobarometro.org/fileadmin/documentos/articulos_y_documentos/The_Part icipation_Gap.pdf

${ }^{[20]}$ Constitución Política de los Estados Unidos Mexicanos.

${ }^{[21]}$ www.alternativa.org.mx

${ }^{[22]}$ www.nueva-alianza.org.mx

${ }^{[23]}$ www.pan.org.mx

${ }^{[24]}$ www.prd.org.mx

${ }^{[25]}$ www.pri.org.mx

${ }^{[26]}$ Código Federal de Instituciones y Procedimientos Electorales. 